\title{
A POSTGRADUATE COURSE IN SPINAL NURSING ESTABLISHED AT THE CONRADIE HOSPITAL, CAPE TOWN
}

\author{
By DR. A. KeY \\ Spinal Injuries Centre, Cape Town
}

The Spinal Cord Injuries Centre at the Conradie Hospital, Cape Town, South Africa, which has been in existence for just over seven years has inaugurated this year a fairly comprehensive postgraduate course in Spinal Unit Nursing. The first five students will complete the first course at the end of July I97I. The establishment of this course and it's recognition by the South African Nursing Council has taken two or three years to achieve. No postgraduate course of less than I2 months duration is recognised as a specialty by the Nursing Council. It was, however, felt that a six-month course in spinal nursing would be sufficient, and it has been agreed that those students who successfully complete the three-hour written and the oral examinations will receive a certificate and a badge which has been specially designed. It was decided to limit the number of students to six per course in order to provide the optimum facilities for sole charge of a ward for a period of three months during the second half of the course. The centre at Conradie Hospital now has I 50 beds in three wards and two students are in charge of each ward for a period of one month.

The first three months are spent full time in college receiving lectures and lecture demonstrations, given by a senior matron tutor who is experienced in spinal nursing and who holds a certificate of competency issued by the Spinal Unit at Stoke Mandeville Hospital. Lectures are also given by the part-time consultant members of our team, the Medical Superintendent of Conradie Hospital, the Senior Medical Officer of the Spinal Unit, the senior physiotherapist, the senior occupational therapist, a representative of the department of social welfare, a laboratory technician, a psychologist and the hospital dietician.

Approximately Ioo lectures are given by the senior matron tutor covering the following subjects:

I. Anatomy and physiology of the spine, central nervous system, urinary system, respiratory system and neuromuscular system.

2. Physics and chemistry.

3. Nursing of the spinal injury case.

4. Ward administration.

5. Team work.

A further 25 lectures are given by the medical and paramedical staff and others as follows:

I. 2 lectures by the medical superintendent on the administration of a spinal unit with special reference to the special facilities required and the staffing of the various departments involved. 
2. 5 lectures by the urology consultant on the management and treatment of the neurogenic bladder and the neurophysiology of the genito-urinary system.

3. 4 lectures by the orthopaedic consultant on the various types of bony injury their management and treatment.

4. 2 lectures by our plastic surgeon on pressure-sore prevention and treatment.

5. 2 lectures by our thoracic surgeon on respiratory complications and treatment.

6. I lecture by our neurosurgeon on the consequences of complete and partial transection of the spinal cord.

7. 2 lectures by the senior medical officer on materia medica giving actions, uses and side-effects of the drugs commonly used and drugs to be avoided in spinal injury cases.

8. 3 lectures by the senior physiotherapist on lifting and turning, physiotherapeutic care of the respiratory system, collars, braces, walking appliances and the types of wheelchairs used.

9. 4 lectures on psychology given by a psychologist who deals with the patients in the unit on defence mechanisms, changes in body and self image and the reaction and adaptation to a new way of life.

IO. I lecture from the hospital dietician on the general principles of diets for the spinal patient.

II. 2 lectures by a representative of the department of social welfare and pensions on disability grants, the Workmen's Compensation Act and family maintenance.

12. I lecture and practical demonstration of the Astrup and other laboratory tests by a laboratory technician.

In addition the students attend the following:

I. Daily ward rounds for a period of approximately io weeks as observers.

2. 6 clinical ward rounds each with the urologist and orthopaedist.

3. Routine observations of all ward and theatre procedures mainly urological but including manipulations under anaesthetic and phenol and alcohol blocks.

4. 4 sessions each of urological and plastic surgery procedures in the operating theatre.

5. 4 team meetings of the entire team which are routinely held fortnightly at our unit.

6. 2 demonstrations routinely given four times annually to student nurses, trained nurses and medical students on the overall treatment and rehabilitation of paraplegics. These are very basic demonstrations but are of value to the student who on returning to another hospital may have to speak on this subject.

7. 2 days with the social workers gaining insight into the problems involved and the services rendered regarding grants, financial assistance in general and assisting patients with their social and family problems.

8. 5 days working with the physiotherapists.

9. 36 turning rounds -6 conducted by each student under supervision.

I0. 2 days of home visits with the Cape Cripple Care social workers. 
II. 2 days working with the occupational therapists in the wards and in the occupational therapy department.

I2. 2 visits to the firm who supply the Bird respirators to learn the principles of the respirator, its care and maintenance.

13. A visit to the medical school for a practical demonstration of the neuromuscular system on cadavers.

I4. A visit to an industrial training centre for the disabled, a Cheshire Home and a hostel for disabled.

I5. Discussion groups at which the students present journal articles and discuss methods of treatment at other spinal centres.

On completion of the three months in college, two students are placed in charge of a ward for one month and are then in sole charge of each of the other two wards for a period of one month each. Included is at least two weeks of night duty. During this period their practical work is assessed. A final week is spent in college and a three-hour written paper, an oral examination and the presentation of a case history follow.

Although the first course has not yet reached completion it has been possible to make the following observations. This first group of five students (a sixth who had enrolled was unable to attend) includes two sisters and one male charge nurse who had, prior to the course, been in charge of a spinal unit ward at our centre for a period of a year or more. Despite this, they themselves, were the first to admit that the course has already been of inestimable value to them. The students had been in charge of the wards for one month up to the time of my departure overseas and the difference in their approach was already most noticeable. They are all much more confident in themselves, are taking a much more keen and active interest in all aspects of therapy and rehabilitation. With their now very much broader knowledge and outlook they are able to assess the patient as a whole taking every aspect into consideration. All credit to our two students to whom spinal nursing was a completely new field, they are equally efficient in the wards as their colleagues who have had previous spinal nursing experience.

With a nucleus of three trained staff of the Conradie Hospital with a certificate in spinal unit nursing in charge of our wards, students of courses to follow will benefit by having the added facility of wards well administered. It is our intention to recruit not only staff from our own hospital but also from hospitals throughout the Republic and elsewhere, and hope, by so doing to assist in the establishment of further much needed units in our country and beyond our borders. This is the first course of its kind established in South Africa and it is open to all trained nurses who wish to avail themselves of this postgraduate study of spinal injury nursing.

Acknowledgment. I wish to thank our senior matron tutor, Miss P. E. Gollop, for her assistance in the compilation of this paper. 